8 César De Santos-Berbel, PhD

9 Assistant Professor

Alessandra Lioi, MSc

PhD candidate

ORCID: $\underline{0000-0003-0812-4094}$

ORCID: 0000-0001-9686-8872

Marco Bassani, PhD

Associate Professor

ORCID: $\underline{0000-0003-2560-1497}$

Associate Professor Madrid

ORCID: $\underline{0000-0001-8941-5795}$

\title{
3D modelling of highway guardrails for sight distance assessment
}

Department of Environment, Land and Infrastructure Engineering, Politecnico di Torino

Departamento de Estructuras y Física de Edificación, Universidad Politécnica de Madrid

Department of Environment, Land and Infrastructure Engineering, Politecnico di Torino

Maria Castro, PhD (corresponding author: maria.castro@upm.es)

Departamento de Ingeniería del Transporte, Territorio y Urbanismo, Universidad Politécnica de

Manuscript accepted in Journal of transportation Engineering, Part A: Systems

https://doi.org/10.1061/JTEPBS.0000593 


\section{Abstract}

Safety barriers limit the severe consequences to occupants of vehicles leaving the roadway from colliding with obstacles, yet they may significantly reduce the available sight distance (ASD). A procedure was devised to accurately recreate highway guardrails in three dimensions (3D), fitting the barriers onto the curve roadsides. The effect of these devices on the reduction of the ASD was thus evaluated in a set of case studies comprising different curve radii overlapped with different vertical alignments and combined each with two safety barriers in two-lane rural roads. The 3D models of highway curves with the selected guardrails were created in a Geographic Information System. Then, a geoprocessing model was used to compute the $A S D$. The results made possible to quantify the $A S D$ reduction produced by the barrier with higher containment level in relation to the highway design parameters, which can assist authorities in developing more comprehensive safety device standards.

\section{Keywords}

Guardrails, Highways, Sight distance, Road safety, 3D modelling 


\section{Introduction}

Road restraint systems are safety devices aimed at protecting drivers and occupants from the consequences of vehicle departure from the carriageway, absorbing the impact energy. Since they contain out-of-control vehicles within the road, the even more serious consequences resulting from an impact against roadside fixed objects or the vehicle rollover are avoided (AASHTO 2018).

Road restraint systems are installed along medians and roadsides, so they limit the driver's ability to see the roadway ahead (Wang et al. 2017). Steinauer and Mayer (1999) observed that on left-hand curves on German motorways crashes are more frequent than on the counterpart righthand curves due to the sight-distance reduction caused by the median barriers. The limitation of the available sight distance $(A S D)$ is often in contrast with the need to guarantee a sufficiently long visible portion of the road ahead where to complete manoeuvres safely. As a result, road designers must satisfy both needs adopting adequate barriers and geometric characteristics preserving a minimum ASD from potential conflict points and/or obstacles along the driving path (AASHTO 2018; Ministerio de Fomento 2016; Ministero delle Infrastrutture e dei Trasporti 2001). Sight distance is one of the most important elements not only in the road design but also in the road management to the aim of traffic safety (Castro et al. 2016). Montella (2001) advocated cost-benefit analyses to choose the most appropriate traffic containment device in terms of safety performance. Consequently, given the effects of safety barriers on the $A S D$, it must be included in such analyses (De Santos-Berbel et al. 2018).

The installation and performance requirements of safety barriers in European countries are regulated by European and national standards. As stated by European standards (CEN 2002, CEN 2011a; b, CEN 2012), barriers are classified according to several containment levels, the entity of the deflection of the system and classes of dissipated impact energy. However, each Member State imposes different minimum requirements based on the road characteristics and operating traffic conditions (Ministerio de Fomento 2009, 2014; Ministero delle Infrastrutture e dei Trasporti 2004). Hence, in similar roads operating under similar traffic conditions, barriers of different characteristics 
may be installed in the same European country, as well as among countries. In this sense, barriers that oversize the minimum standard requirements may be selected in a precautionary way while significantly altering sight-distance conditions.

The selection of roadside barriers for new construction or safety upgrading involves contemplating the combined effect of highway geometrics with limited sight distance (AASHTO 2011). Sarhan and Hassan (2012) investigated the effect of different concrete barriers on the ASD for the stopping maneuver. Nevertheless, studies addressing the impact and consequences in terms of sight distance of installing different guardrails, which have a more complex three-dimensional (3D) shape than concrete barriers, have not been found in the literature. Furthermore, it has been evidenced that small differences in accuracy of 3D road items might produce significant variations in the $A S D$ estimation (Bassani et al. 2019; Iglesias et al. 2019). As a consequence, the 3D modelling of road barriers must be carried out with the highest accuracy and precision.

This research aims to devise an advanced procedure to accurately recreate highway sections with guardrails in 3D. Moreover, the procedure was tested for evaluating the effect of two different guardrails on the $A S D$ on curves in relation to the highway design parameters.

The paper is divided into five sections. The introduction is followed by a review of the current state of the art. A subsequent section outlines the procedure devised to recreate the guardrails and describes the organization of the case studies. The next section summarizes and discusses the results obtained from the study. Conclusions and brief considerations about future research are presented in the last section.

\section{Related works}

The ASD is the maximum length of the road stretch ahead measured along the future path that the driver can see in the presence of sight obstructions, i.e. elements of the roadway and/or the roadside (Castro et al. 2016). Figure 1 illustrates how the $A S D$ is measured along the vehicle trajectory as the distance between the farthest point visible (D, detected from the intersection between the line of 


\section{(1)}

sight - LOS - and the trajectory itself) and the point of view (A). From the point of view A, straight lines may be built to link target points along the future path $(B, C, D, \ldots G) ;$ lines $A B, A C, \ldots$, and $A G$ are sight lines from the driver's eyes. Since the lines AE and AF intersect the sight obstruction (the HI element), the driver cannot see the road stretch from E to F. Hence, he/she can only see the sections from $A$ to $D$ and from $G$ : the $A S D$ is, therefore, the $\operatorname{arc}$ length from $A$ to $D$.

For safety reasons, the $A S D$ must be greater than the distance used to stop the vehicle before hitting an unexpected object along the lane (i.e., the stopping sight distance, SSD). Consequently, the $A S D$ may be considered in the evaluation of safe speed limits. The comparison between ASD and SSD allowed assessing the influence of sight distance on road safety. Ibrahim and Sayed (2011) incorporated stochastic risk measures due to insufficient sight distance to a crash prediction model to evaluate the potential impact of horizontal curve design on the collision frequency. By analysing top crash-prone segments, Gargoum and El-Basyouny (2020) showed that the crash frequency is 2 to 3 times higher where the required SSD is not met.

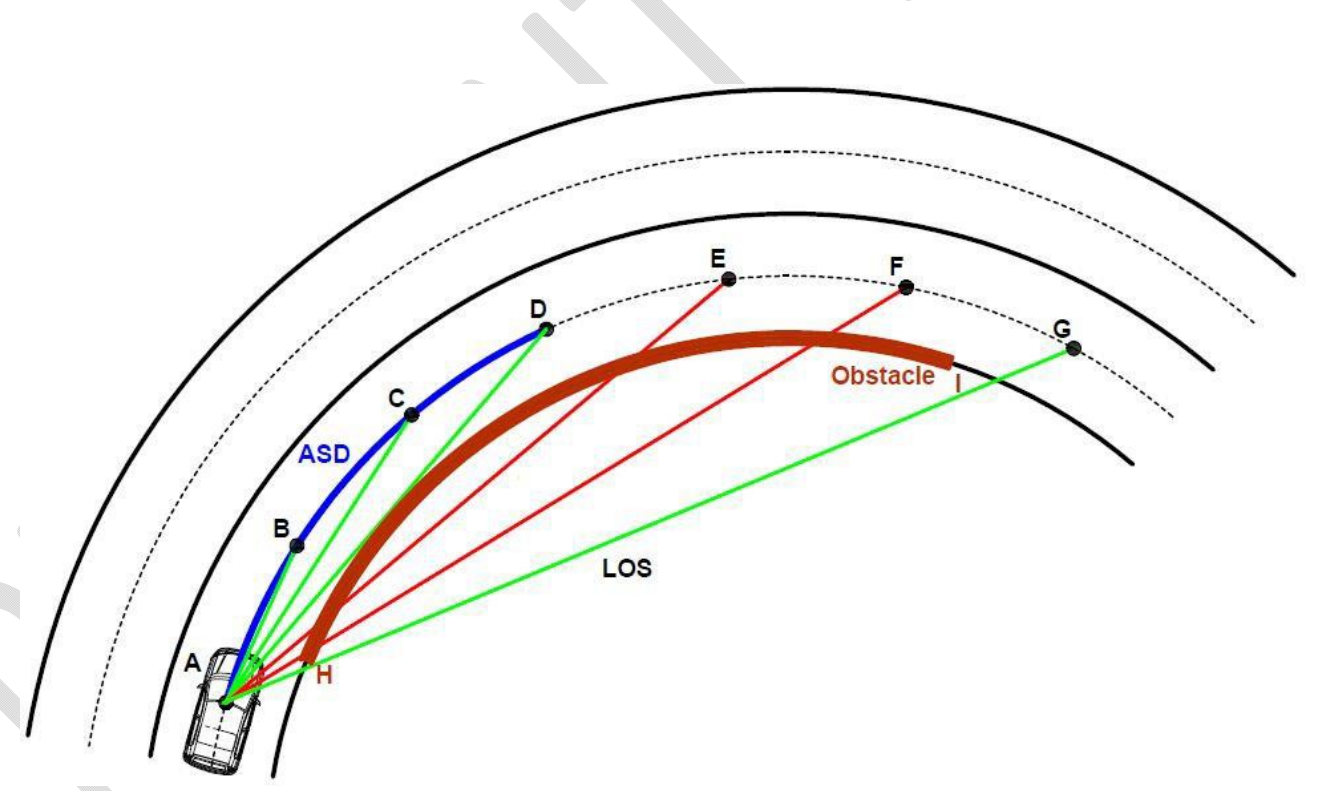

Figure 1. Graphical definition of the available sight distance (ASD). 
eye and the height of a possible obstacle, with the driver's head position located at $1.1 \mathrm{~m}$ above the pavement surface. Different obstacle heights are assumed in the assessment of ASD to check the compliance with the SSD requirements: $0.1 \mathrm{~m}$ with the Italian standard, and $0.5 \mathrm{~m}$ with the Spanish one. For research purposes, the heights of target may be differentiated from the standard values. De Santos-Berbel and Castro (2018) set the driver's eye heights at $1.5 \mathrm{~m}$ and $2.0 \mathrm{~m}$ to simulate sightdistance scenarios with heavy vehicles in the vicinity of underpasses, producing relevant variations in the $A S D$ outputs.

The ASD depends on cross-section elements, roadside features, and horizontal and vertical alignment (Ismail and Sayed 2007). On existing roads, reduced sight distance may be caused by inadequate geometric design, changes in the initial roadside conditions due to natural or human actions, or both (De Santos-Berbel et al. 2013).

Although most current design policies contemplate the two-dimensional (2D) approach to evaluate the $A S D$, the literature suggests that a $3 \mathrm{D}$ approach is much more reliable to avoid overestimation or underestimation of the ASD (Castro et al. 2017). De Santos-Berbel et al. (2018) studied and compared the differences between the output of 2D and 3D ASD analyses produced by concrete barriers on curves on existing highways. The results found significant differences between both procedures. Particularly, the superelevation, the effect of which could be included in the 3D procedure, was found to affect the results. Papadimitriou et al. (2018) highlighted the need to consider the combined effect of 3D alignments alloys and the presence of containment devices.

Many methods and algorithms have been developed and validated for the evaluation of the $A S D$. Several authors have proposed ASD estimation procedures based on modelling the surface of the roadway and roadside features to recreate the highway and its environment (Castro et al. 2014; Ismail and Sayed 2007). Liu (2013) developed an analytical method to determine the available sight distance on combinations of vertical and horizontal curves in the presence of roadside barriers. These procedures have shown limitations to represent overhanging features in the road environment. Alternatively, Campoy-Ungría (2015) suggested an ASD estimation method based on prismatic line-of- 
137 sight buffers launched directly on a high-density LiDAR cloud of points, not requiring any terrain surface. More recently, fully 3D methods have been developed and validated to obtain reliable ASD results (Gargoum et al. 2018; Ma et al. 2018; De Santos-Berbel and Castro 2018). to obtain point clouds to be used to accurately create 3D models of real driving scenarios along road sections (Alcón Gil et al. 2021; Bassani et al. 2015; Ma et al. 2018; Shalkamy et al. 2020) and intersections (Jung et al. 2018). The difficulties inherent in the use of MLS techniques stem, on the one hand, from the strong dependence of the ASD analysis on the accuracy of the objects modelled in the near environment and its modelling procedure to subsequently obtain realistic $A S D$ values. Hence, a dense cloud of points is required to enable a proper modelling of the shape of elements that may represent a sight obstruction (Bassani et al. 2019; Iglesias et al. 2019). As a result, a significant amount of data and storage capacity are necessary, with a significant share of data points that are not effectively necessary for the analysis (i.e., inefficient). On the other hand, the use of MLS is, in principle, limited to real scenarios and is not suitable to be used in road design scenarios. Nevertheless, the procedure utilized in this study is capable of incorporating 3D features derived from MLS surveys along with virtual new elements to recreate different scenarios (Alcón Gil et al. 2021; De Santos-Berbel and Castro 2018).

To lighten the computational burden and related costs to carry out sight distance calculation, Ma et al. (2019) have introduced the use of a convolutional neural network that enables the estimation of the ASD using far fewer points. This algorithm improves the above reported inefficiencies related to the use of large databases from MLS, partially solving the former of the two issues abovementioned.

Spatial analysis and environment modelling capabilities of geographic information systems (GIS) have led to the development of ASD estimation procedures (Khattak and Shamayleh 2005). Castro et al. (2011) provided a 3D approach based on viewsheds to evaluate ASD by using GIS tools. Later on, 
sight. Bassani et al. $(2016,2019)$ evaluated the $A S D$ in an urban road scenario where several sight obstruction types are present, intending to highlight and compare the computational efficiency, advantages and drawbacks of GIS and numerical computing codes.

The use of a GIS in highway sight distance studies can help solve part of the difficulties in the use of traditional design software because it can be employed to carry out other geometric and safety analyses. For example, consistency and safety analyses are carried out overlapping with GIS the information coming from crash counts, operating speeds, traffic data, road features, and geometric characteristics of a highway (Castro and De Santos-Berbel 2015; Iglesias et al. 2016). Furthermore, the detection of shortcomings and hidden dips in the 3D alignment can also be carried out in the GIS environment (Castro et al. 2017; Castro and De Santos-Berbel 2015). Road design standards and guides can be used in a GIS to generate realistic 3D road models starting from 2D data including centreline and basic cross-sectional information (Wang et al. 2014). Current GIS applications are robust enough to model road elements and obtaining results comparable to those coming from sight inspections. Finally, GIS is a flexible tool that can also overcome the limitation of MLS based techniques because it can easily include 3D sight obstructions, e.g. objects in the roadside like poles, installations, and safety barriers.

\section{Methodology and materials}

This section outlines the procedure to build up the 3D model of the horizontal curves with the selected guardrails for the assessment of the ASD. The computer software used to analyse the 3D models is also described.

\section{D modelling: barrier design}

The importance of accurately and precisely modelling the road and its environment in 3D, guardrails included, stems from obtaining reliable results from the analysis. In this sense, these devices must be accurately recreated and adapted to the roadside for any given highway alignment layout. The 
assessment of the ASD contemplated two different types of guardrails. The first one is a 2-wave N2-type guardrail, which reflects the guardrail typically installed on Spanish two-lane rural highways. The second one is a 3-wave H2-type guardrail, widely used in Italy on the same road type. The process devised to create the 3D barrier models is illustrated in Figure 2. All the relevant components of their profile were drawn on computer-aided design software. It is worth noting that the considering elements must be represented with closed lines to facilitate the operations in 3D drawing software used later.

The cross-section drawings displayed in Figure $\mathbf{3}$ were imported into SketchUp Pro to create the 3D models. Then, the barrier beam was extruded along a straight guideline perpendicular to the plane containing the beam cross-section. This guideline, represented by the red dotted line in Figure 4, serves in turn as the reference line for the installation of the barrier since it is located at the same height as the base of the posts and in the same vertical position as the generating line of the beam closest to the road centreline. Next, the barrier posts were replicated and inserted at the specified fixed distances throughout the barrier ( $4 \mathrm{~m}$ for the $\mathrm{N} 2$ type, $2 \mathrm{~m}$ for the $\mathrm{H} 2$ type), thus obtaining the 3D model of the guardrails displayed in Figure 4.

The straight barrier displayed in Figure $\mathbf{4}$ serves as a template to create the required barrier models for any highway alignment. SketchUp Pro was selected to take advantage of the CLF Shape Bender extension, which makes it possible to adapt a given shape, not necessarily with a homogeneous cross-section, to a 3D curve given a guideline for the original shape and another guideline for the target shape (Trimble 2013). 


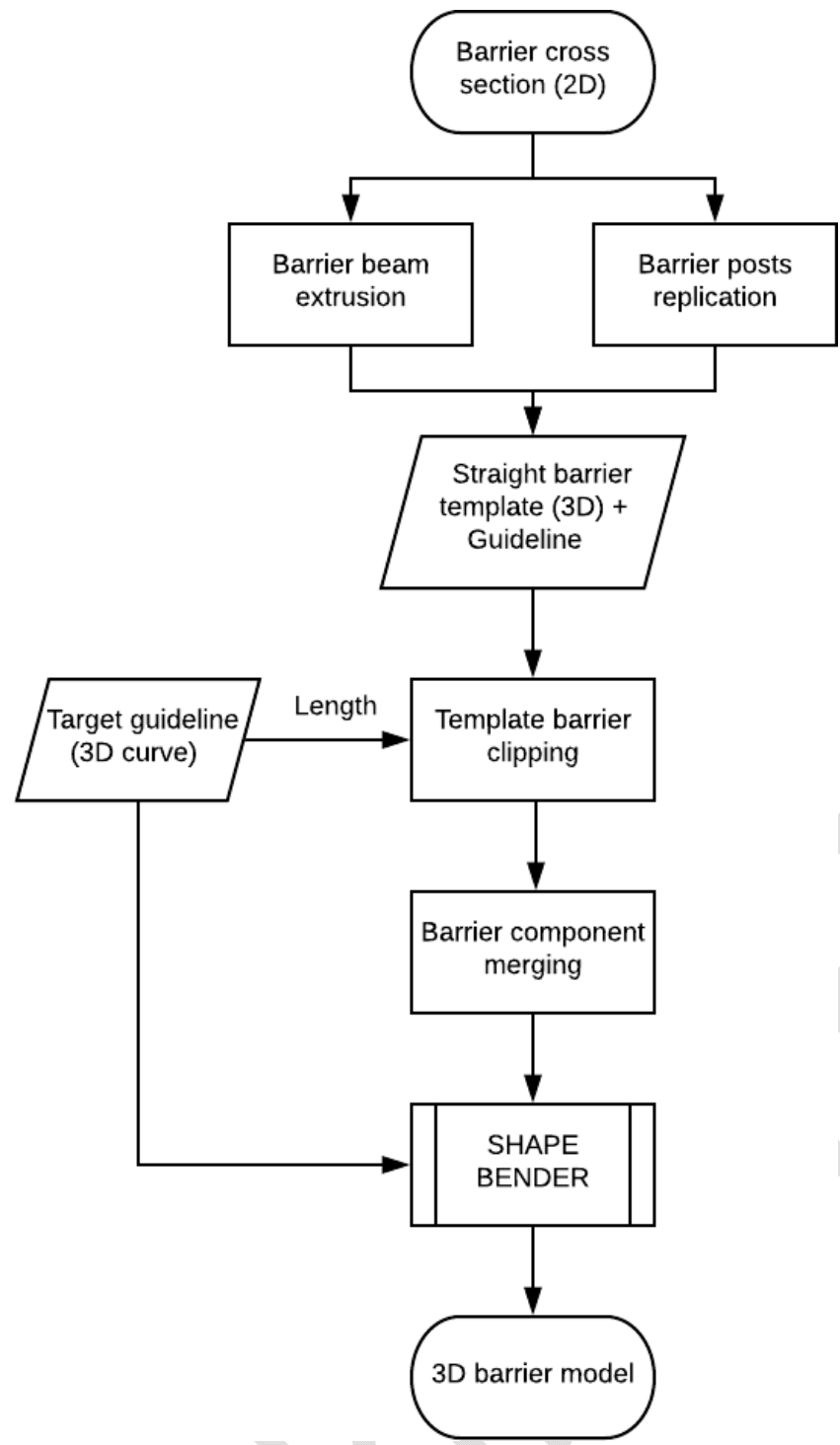

210 Figure 2. Flowchart of the 3D barrier model creation process.

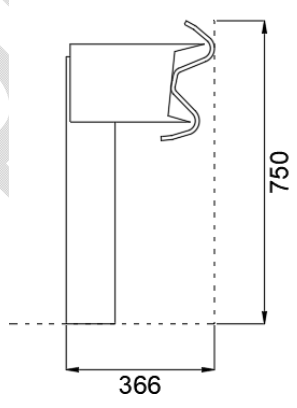

(a)

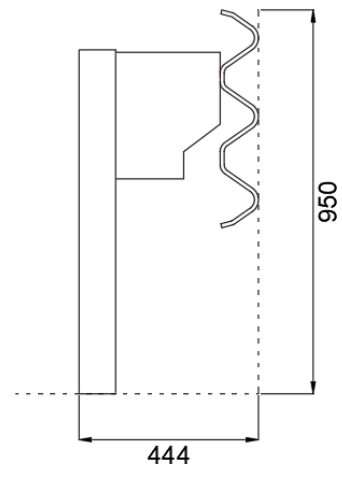

(b)

214 Figure 3. Cross-sections of $\mathrm{N} 2$ (a) and H2 (b) metallic barriers (unit of measurement: $\mathrm{mm}$ ). 


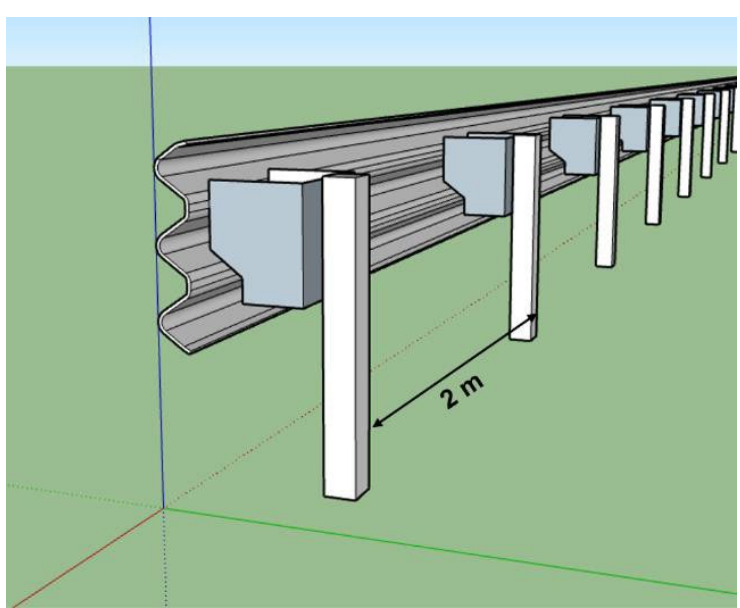

(a)

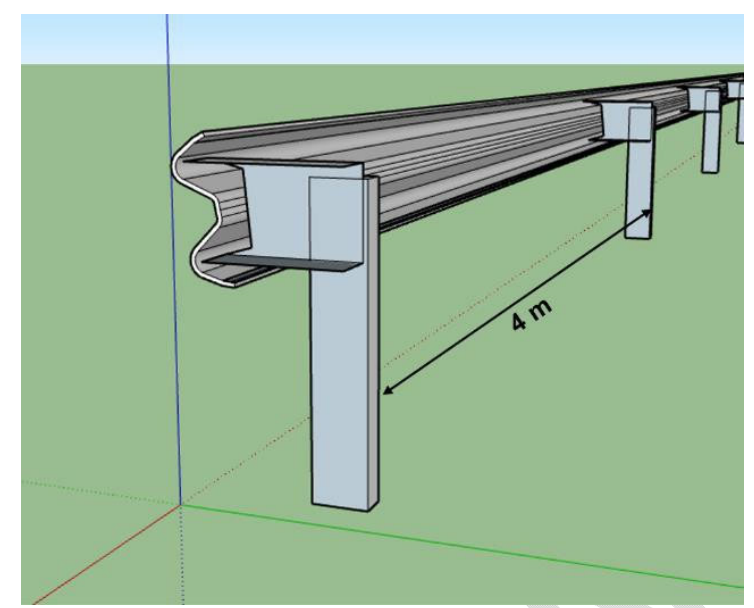

(b)

Figure 4. 3D view of N2 (a) and H2 (b) selected guardrails in SketchUp Pro.

To create a barrier that suits the highway curve in 3D, the 3D curve featuring the roadway inner edge was imported into SketchUp. Next, for producing a barrier without longitudinal distortion, the straight barrier template and its guideline were clipped with length equal to that of the target guideline. Then, all the resulting guardrail components were merged into a single object as required to launch the Shape Bender extension. The 3D guardrail models thus produced were exported as Collaborative Design Activity (COLLADA) format and then imported into a multipatch feature in ArcScene (3D GIS environment), where they were placed in their final position (Figure 5). A multipatch feature is a GIS entity whose specific data represent the outer surface of an object, which occupies a volume in the 3D space (ESRI 2008).

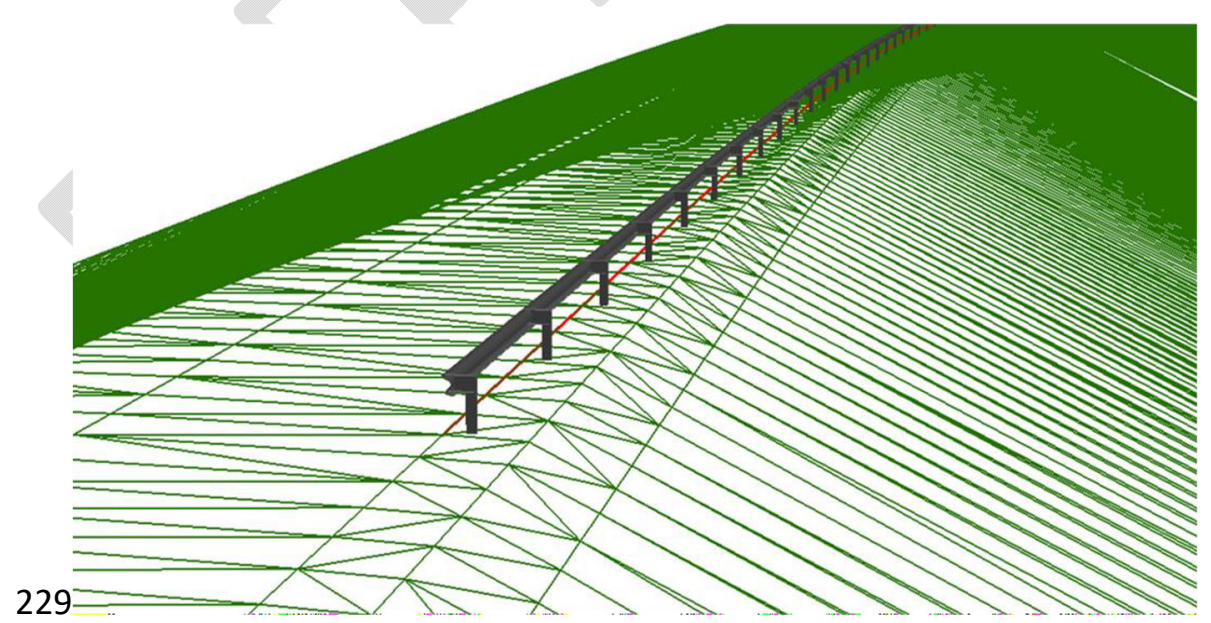

Figure 5. 3D view in ArcScene of $\mathrm{N} 2$ guardrail inserted on the TIN model and fitted to the roadside (red line). 


\section{Geoprocessing model}

Whereas the feature classes representing different types of barriers as visual obstructions that comprise the 3D model were laid out in the 3D environment of ArcScene, the evaluation of the ASD was run in ArcMap 10.3. This allowed boosting computation performance while maintaining the 3D nature of the highway model. Numerical results were obtained by using a GIS geoprocessing model developed and validated by the authors (Iglesias et al. 2016; De Santos-Berbel and Castro 2018). This geoprocessing model is based on tools from the 3D Analyst extension of ArcMap and it permits to consider 3D visual obstacles. First, "Construct sight lines", which connects the positions in space of the driver's eye point and the target points (ESRI 2021a). Then a sequential automatic selection of the generated line feature class input the "line of sight" tool along with the elevation model and the multipatch feature class (ESRI 2021b). It evaluated whether each line of sight is obstructed by any of the model features and, if so, returns a new point feature class containing the exact position in space where the lines of sight were obstructed. In addition, the geoprocessing model outputs the sight distance evaluation results from which the $A S D$ values are retrieved.

The data required to execute this geoprocessing model includes the theoretical path followed by a vehicle (with stations spaced $5 \mathrm{~m}$ apart) and the elevation model which recreates the highway and its roadsides. In general, two types of elevation models are available: digital terrain models (DTM) and digital surface models (DSM). A DTM is a 3D representation of the terrain surface which includes exclusively the elevation of the bare ground, without vegetation, traffic signs, or buildings. On the other hand, DSMs consider the structures on the surface, also detecting overhanging features. Nevertheless, when overhanging features are present by the roadsides (as in the case of safety barriers), the intrinsic features of DSMs do not support two points on its surface having the same horizontal projection and different elevation values (Iglesias et al. 2016; De Santos-Berbel and Castro 2018). To overcome this problem, the highway 3D model was built up combining a DTM and fully-3D modelled landscape features. The former was built up in GIS from a cloud point created using CLIP version 1.29 road design software (TOOL S.A. 2013). The point cloud was created from the most 
relevant points of road cross-sections spaced 1 meter apart. Next, a triangular irregular network (TIN) (surface defined by the mesh in Figure 5) was built considering the point cloud as the node set. The later comprises the multipatch feature classes modelling the guardrail as a sight obstruction. The procedure allows to include mass standardized constructive elements into the highway 3D model in the GIS environment. Therefore, the method hereby presented provides reliable results thanks to the incorporation of lifelike-modelled 3D objects.

It must be noted that guardrails do not constitute a simple continuous obstacle like vertical surfaces (e.g., walls, rigid concrete barriers), but they might enable the driver to perceive the road ahead through the spaces between posts beneath the barrier beam. In this sense, the capability of the geoprocessing model to return the 3D position of the visual obstruction and identify the visual obstacle that obstructed each line of sight made it possible to accurately assess the $A S D$ in the presence of guardrails contemplating its complex 3D shape.

Furthermore, the driver's eye height and the target height are two required input parameters of the geoprocessing model. Their values were taken according to the Spanish highway design standard, as 1.1 and $0.5 \mathrm{~m}$, respectively (Ministerio de Fomento 2016).

The algorithm first launches sightlines connecting the driver's point of view and targets located along the vehicle path ahead, up to a prespecified maximum distance. Next, it checks whether the sightlines are obstructed or not by either the DTM or the inserted multipatch features and retrieves the $A S D$ values.

\section{Experimental design}

To test the procedure for building up 3D models, a set of highway alignments was created. Nine horizontal curves were designed with different radius, each one connected to spirals at both ends. Two alternative vertical profiles were designed for each curve: a flat-grade profile and a profile with vertical curves overlapped to each horizontal curve according to the alignment coordination principles (Ministerio de Fomento 2016; Ministero delle Infrastrutture e dei Trasporti 2001). The cross-section 
consists of a 7-m wide travelled way with two lanes ( $3.50 \mathrm{~m}$ each), one per driving direction, and 0.5 $\mathrm{m}$-wide shoulders. Since the guardrail was placed in such a way that the horizontal projection of the innermost generatrix of the beam coincides with the outer edge of the shoulder, the lateral offset with respect to the travelled way was $0.5 \mathrm{~m}$. In terms of design speeds, radii, and superelevation of curves, two categories of roads can be distinguished, the so-called Group 2 and Group 3 according to the Spanish standard denomination for undivided highways (Ministerio de Fomento 2016).

The geometric features of the horizontal curves are provided in Table 1. The length of each curve has been laid out to ensure that the ends of the lines of sight that determine the minimum ASD associated to the curve lie within the bounds of the circular arc of the curve on both travelling directions. Table 1 also includes the parameter $K_{V}$ (equation 1 ) of the overlapped vertical curve. Negative $K_{V}$ values correspond to vertical crest curves while positive ones correspond to vertical sag curves. Design speeds in Group 2 range from 120 to $80 \mathrm{~km} / \mathrm{h}$ at intervals of $10 \mathrm{~km} / \mathrm{h}$. In Group 3, design speeds range from 80 to $50 \mathrm{~km} / \mathrm{h}$. The design speed values are associated to the minimum radius allowed in a highway segment as indicated in Table 1.

$$
K v=100 \cdot L / \theta
$$

where $K_{V}$ is the vertical curve parameter in $\mathrm{m}, L$ is the length of vertical curves in $\mathrm{m}$, and $\theta$ is the absolute value of the algebraic difference between the outbound $i_{2}$ and inbound $i_{1}$ grades in $\%$.

To carry out the sight-distance analysis using the geoprocessing model, either guardrail model was set by the inner roadside of each curve. The ASD estimation was repeated for both travelling directions. 
Table 1. Geometric characteristics of the horizontal curves. The negative value of $K_{V}$ indicates a crest vertical curve (group 2), a positive value represents a sag vertical curve (group 3).

\begin{tabular}{|c|c|c|c|c|c|c|}
\hline Group & Section & $\begin{array}{l}\text { Horizontal } \\
\text { radius }(\mathrm{m})\end{array}$ & $\begin{array}{c}\text { Design speed } \\
(\mathrm{km} / \mathrm{h})\end{array}$ & $\begin{array}{l}K_{V} \\
(\mathrm{~m}) \\
\end{array}$ & $\begin{array}{c}\text { Superelevation } \\
(\%)\end{array}$ & $\mathrm{SSD}(\mathrm{m})$ \\
\hline \multirow{5}{*}{2} & Curve 1 & 700 & 120 & - 38467.98 & \multirow{5}{*}{8} & 261.49 \\
\hline & Curve 2 & 550 & 110 & - 30218.00 & & 216.79 \\
\hline & Curve 3 & 450 & 100 & - 24718.02 & & 178.59 \\
\hline & Curve 4 & 350 & 90 & - 19218.05 & & 145.48 \\
\hline & Curve 5 & 250 & 80 & - 13718.10 & & 116.85 \\
\hline \multirow{4}{*}{3} & Curve 6 & 265 & 80 & + 14617.94 & & 116.85 \\
\hline & Curve 7 & 190 & 70 & + 9515.16 & & 91.17 \\
\hline & Curve 8 & 130 & 60 & +6750.37 & & 69.67 \\
\hline & Curve 9 & 85 & 50 & +4198.36 & & 51.73 \\
\hline
\end{tabular}

308

As previously stated, the $A S D$ along a highway section must meet the distance needed for vehicles to stop (i.e., $A S D \geq S S D$ ). $S S D$ is measured from the driver's position at the time when the obstruction appears and justifies the braking. It includes two contributions: the distance covered by the vehicle from the instant the driver perceives the obstacle to the instant the brake is applied (i.e., the perception and reaction distance) and the distance needed to stop from the instant the braking maneuver begins (i.e., the braking distance). SSD in $\mathrm{m}$ is evaluated according to Equation 2:

$$
S S D=\frac{V \cdot t}{3.6}+\frac{V^{2}}{254 \cdot\left(f_{I}+i\right)}
$$

where $V$ is the design speed in $\mathrm{km} / \mathrm{h}, t$ is the perception and reaction time $(2 \mathrm{~s}$, according to the Spanish standard (Ministerio de Fomento 2016), $f_{i}$ is the longitudinal friction coefficient (as a function of the design speed), and $i$ is the longitudinal grade in \%. Table 1 provides SSD values for this experiment. In this assessment, the longitudinal grade was neglected due to its small values. Figure 6 gives the flow chart of the sight distance analysis. 


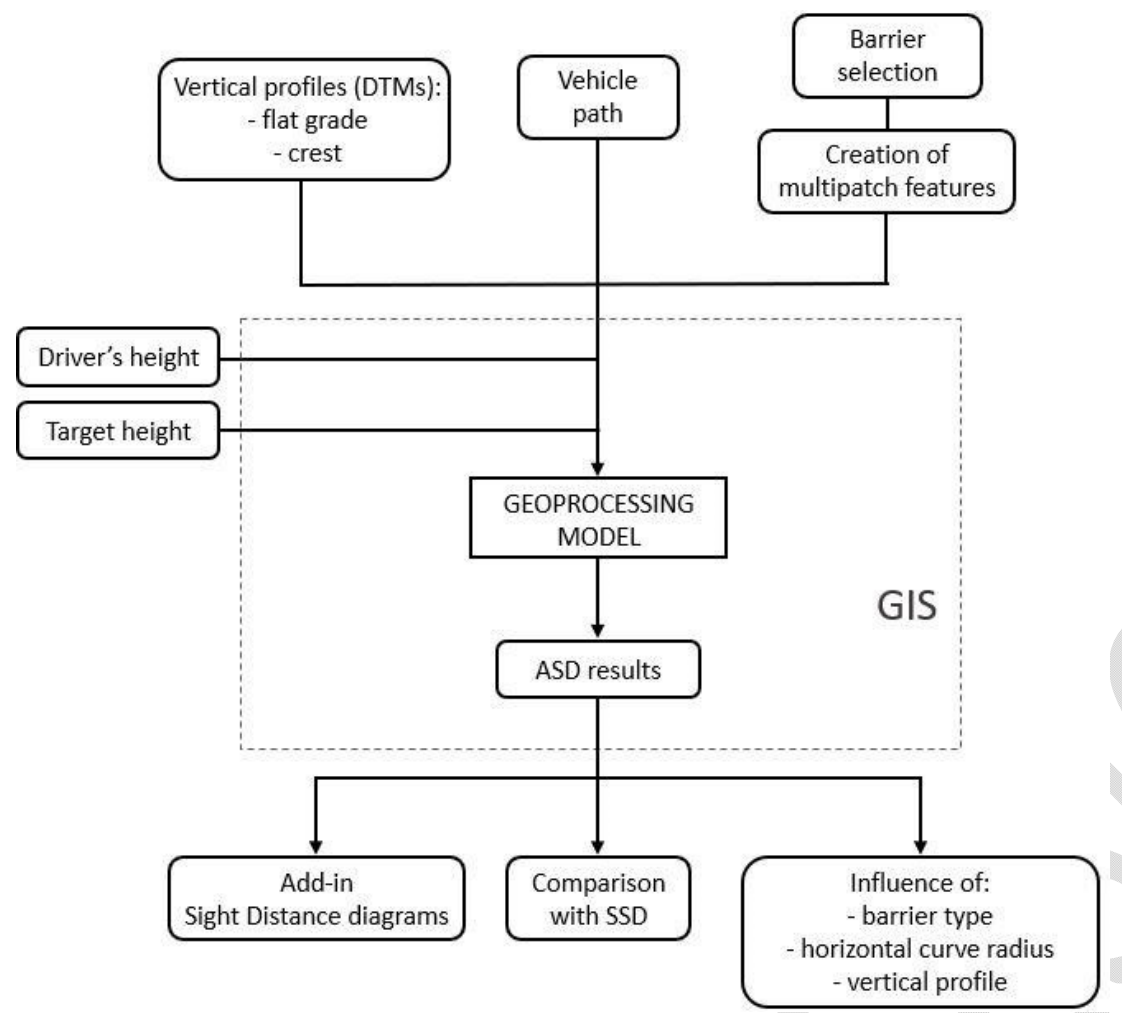

323

Figure 6. Flow chart of the research study.

By setting the vehicle trajectory and the roadside features, the geoprocessing model elaborated the sight distance diagrams with both profiles. Once the ASD values had been extracted, the impact of the barrier type on the $A S D$ in function of the horizontal curve radius and the vertical profile was determined.

\section{Results and discussion}

The minimum ASD values obtained for each alignment on either travelling direction combined in turn with either guardrail model have been extracted. The aforementioned capability of the geoprocessing model to identify the position and the visual obstacle at which lines of sight are intercepted made it possible to assert that in the case studies the ASD limitation was produced by the barrier beam. Although lines of sight might pass through the gap between the barrier posts, it was checked that these lines did not affect the ASD output since the limiting feature was found to be the barrier beam in all cases. 
First, horizontal curves overlapped with the flat-grade profile were analyzed with either barrier, discerning between left-hand and right-hand curves (Figure 7). Considering that in the absence of visual obstructions the $A S D$ would be unlimited, a reduction of the $A S D$ is observed in all the curves due to the presence of barriers.

On left-hand curves overlapped with flat-grade profile (Figure 7a), the ASD is greater than the required SSD in all group 3 curves (those with smaller radius) with both barrier types. A greater decrease of the $A S D$ with the $\mathrm{H} 2$ guardrail due to its higher size is evident. This reduction in $A S D$ increases as the radius of the curve increases too. For curves of Group 2, the $A S D$ met the required SSD in the presence of the 2-wave N2 barrier, except for the curve with $R=700 \mathrm{~m}$ (ASD $=260 \mathrm{~m}$ vs. $S S D=216.8 \mathrm{~m}$ ). The 3-wave $\mathrm{H} 2$ barrier does not allow the ASD to meet the required SSD in curves with a larger radius (e.g. $A S D=210 \mathrm{~m}$ vs. $S S D=261.5 \mathrm{~m}$ for $R=700 \mathrm{~m}$ ).

In right-hand curves (Figure 7b), barriers do not guarantee the required SSD in almost all the analysed cases, with a greater obstruction given by the 3-wave $\mathrm{H} 2$ barrier. The greatest sight distance deficits are observed for the largest radii: with the $\mathrm{H} 2$ barrier, the ASD values are lower than half of the required SSD (e.g. $A S D=120 \mathrm{~m}$ vs. SSD $=261.5 \mathrm{~m}$ for $R=700 \mathrm{~m}$ ). The $\mathrm{N} 2$ guardrail provides $A S D$ always larger than SSD only curves of smaller radius (e.g. group 3, $A S D=55 \mathrm{~m}$ vs. $S S D=51.7 \mathrm{~m}$ for $R=85 \mathrm{~m})$.

As expected, results depict that the installation of 2-waves guardrails is less unfavorable than

the installation of 3-waves ones in terms of sight distance. All else being equal, the ASD is greater in left-hand bends, while in right-hand curves it is more difficult to guarantee it, especially in curves with larger radii.

Since there are two different cases for vertical profiles (flat-grade and with vertical curves), it is possible to compare the effect of the same barrier in different vertical alignments. Figure 8 shows the analyses for $\mathrm{N} 2$ barrier, while Figure 9 those for $\mathrm{H} 2$ guardrail. 


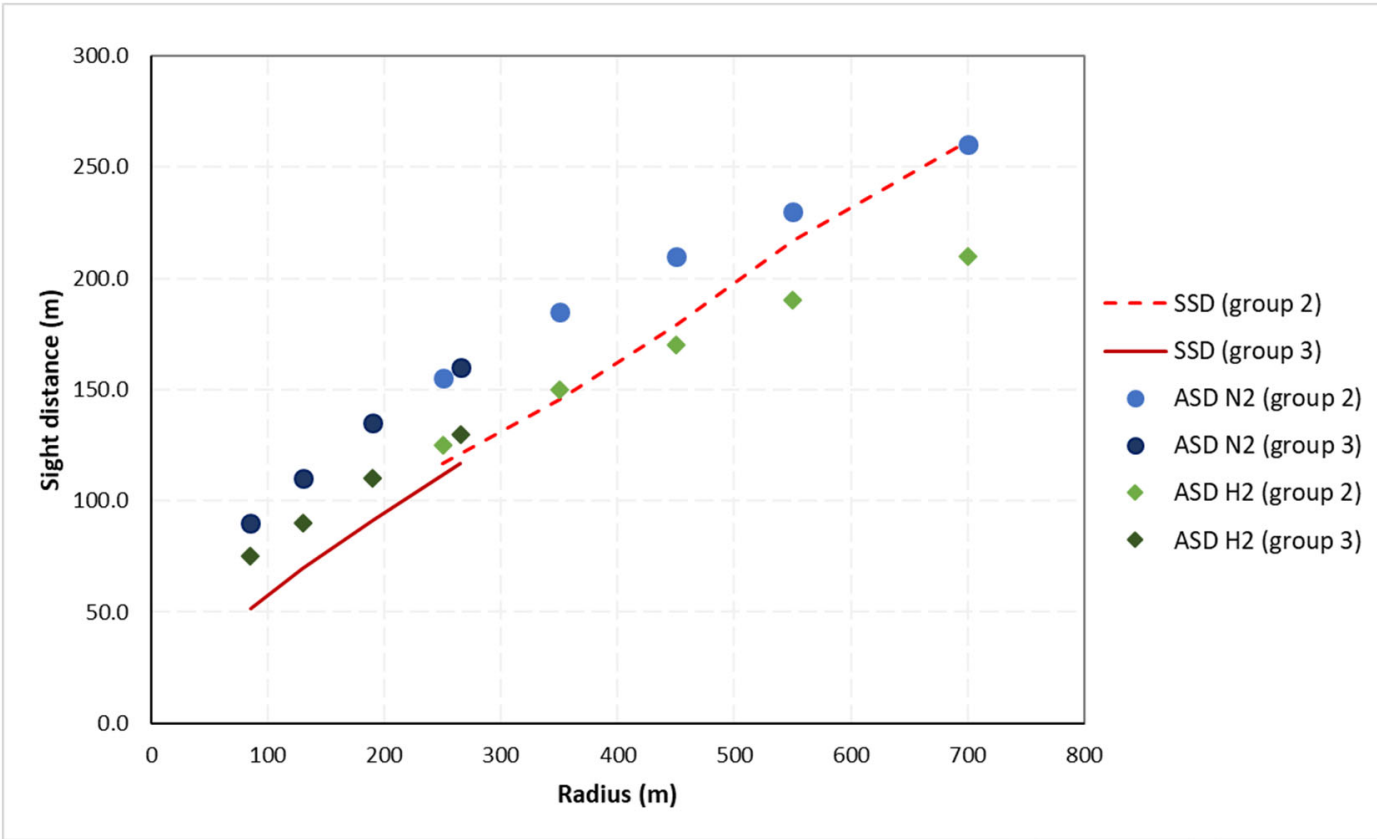

a)

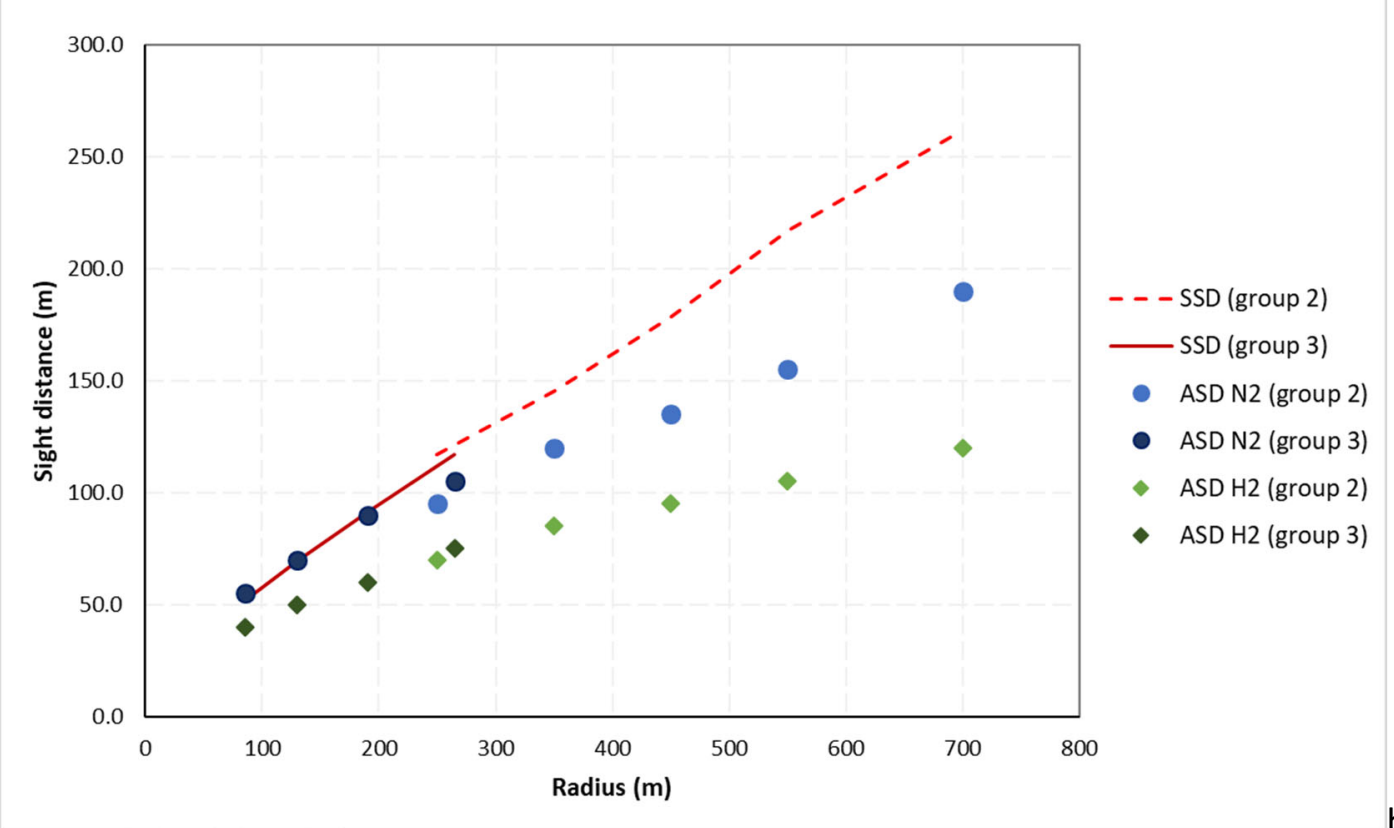

b)

364

365

366

367

368

369

370

371 $372 A S D$ to meet the required SSD in curves with a larger radius (e.g. $A S D=225 \mathrm{~m}$ vs. SSD $=261.5 \mathrm{~m}$ for

Figure 7. Sight distance analysis as a function of the radius on horizontal curves overlapped with flat grade: a) left-hand curves, b) right-hand curves.

Considering the N2 barrier in left-hand curves (Figure 8a), the ASD is greater than the required SSD in all group 3 curves for both types of vertical profiles (flat and sag). The greatest ASD values are reached in the non-flat profile, with sag vertical curves. For group 2 curves the SSD is always guaranteed in the flat-grade terrain. However, the vertical profile with crest curves does not allow the $R=700 \mathrm{~m})$. 


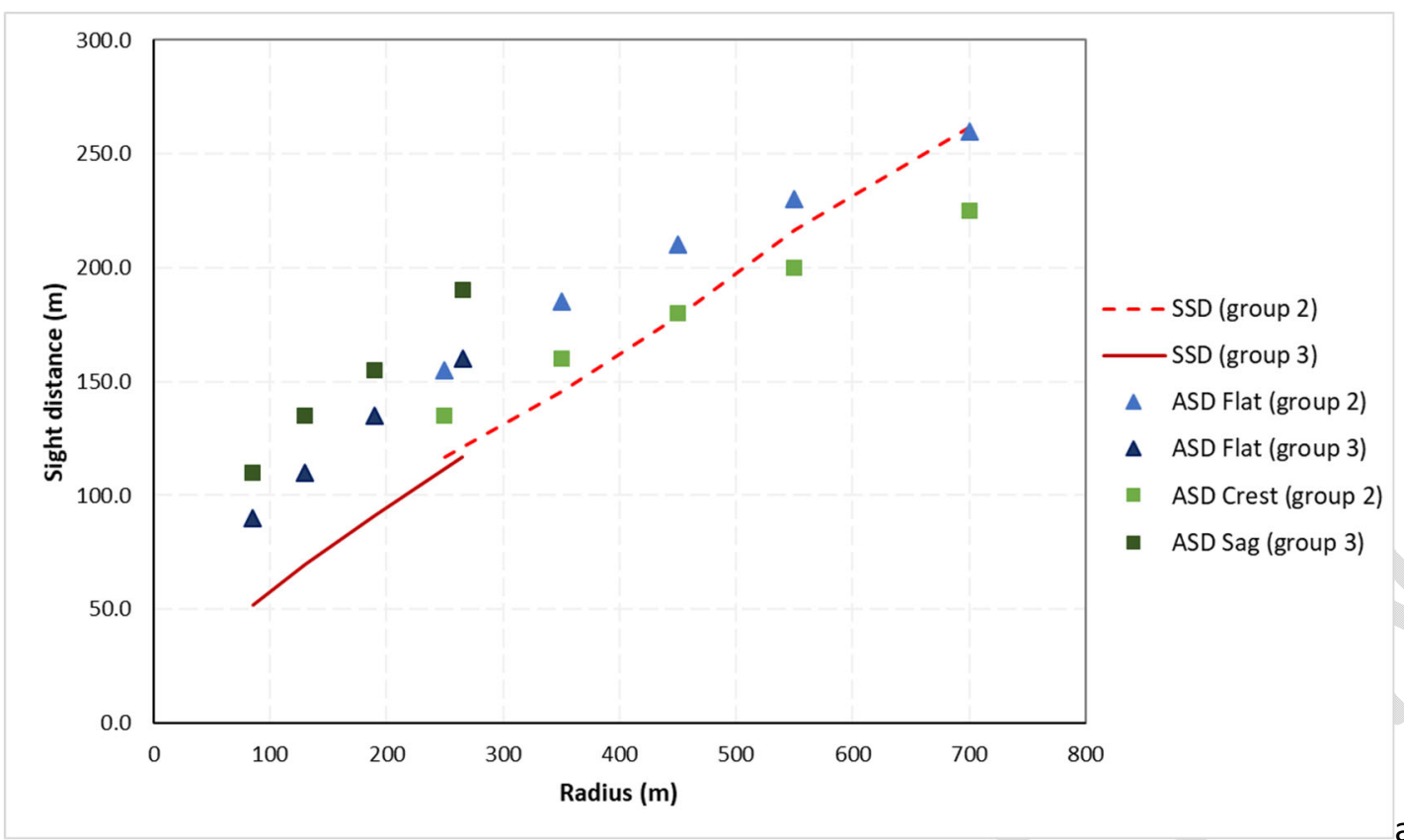

a)

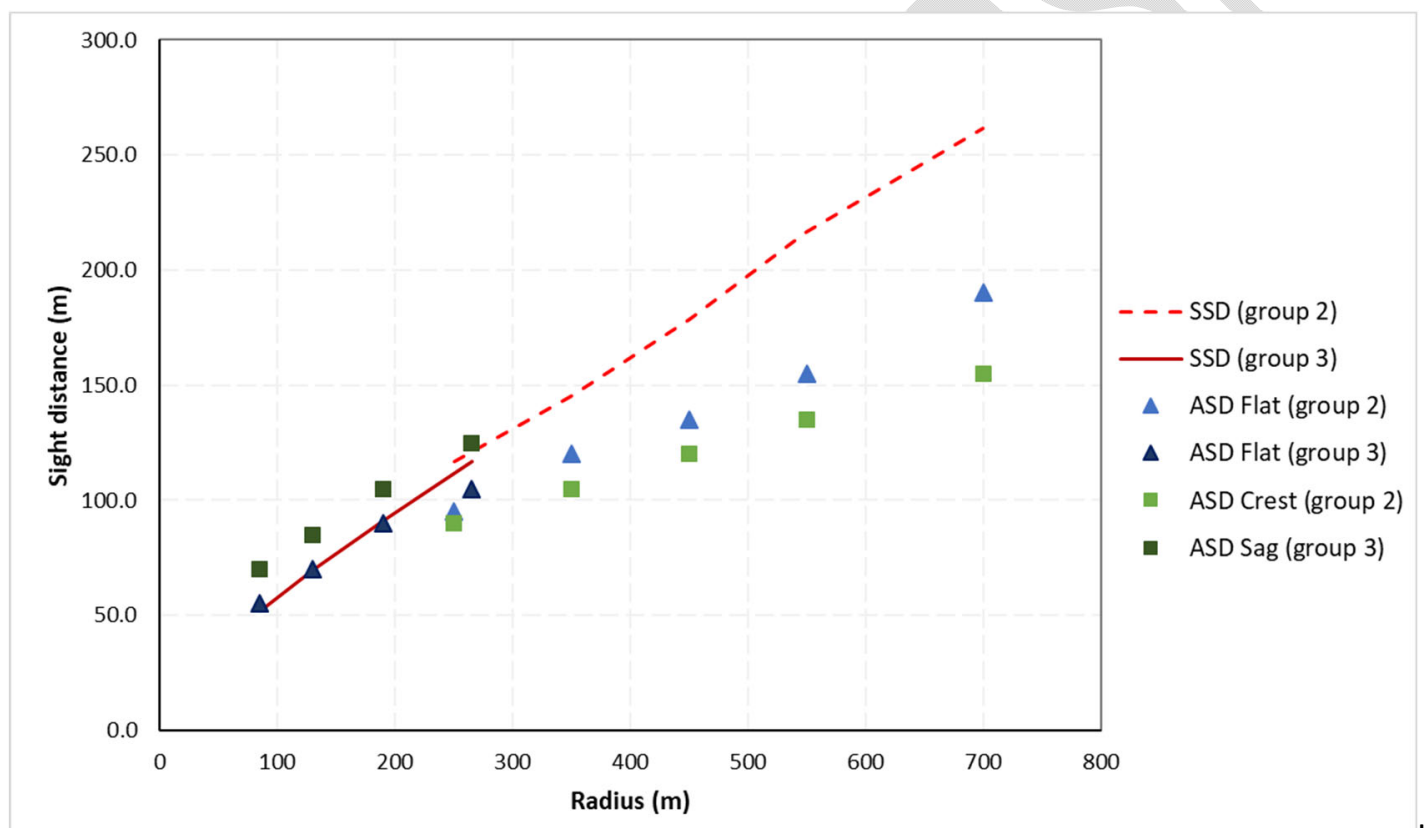

b)

Figure 8. Sight distance analysis in function of the radius on horizontal curves overlapped with N2 barrier: a) left-hand curves, b) right-hand curves.

Even considering two different vertical profiles, the situation in terms of $A S D$ is critical for right-hand curves (Figure 8b). For group 3 curves, the sag vertical profile guarantees $A S D>S S D$ in all curves; $A S D$ values are lower than the required SSD for the group 2 curves, with both vertical profiles, especially with the flat-grade terrain.

By setting the $\mathrm{H} 2$ barrier in left-hand curves (Figure 9a), the ASD values exceeded the required SSD in all group 3 curves with both types of vertical profiles (flat and sag). In this case, sag vertical 
curves provide better sight conditions as well. A different situation occurs for group 2 curves, where the $A S D$ meets the required $S S D$ just in the flat-grade terrain in the smallest curvature radii of the category (e.g. $A S D=125 \mathrm{~m}$ vs. $S S D=116.8 \mathrm{~m}$ for $R=250 \mathrm{~m}$ ). This trend is again justified by the vertical profile: if the sag vertical curve provides a better sight distance, the crest one decreases the length of the road visible from the driver point of view.

In right-hand curves (Figure 9b), sight conditions do not comply with safety requirements in the presence of $\mathrm{H} 2$ guardrail, and the difference between $A S D$ and SSD increases as the curve radius increases. $A S D$ values for the flat-grade terrain and crest curve vertical profile are almost identical; in particular, in group 2, they coincide. This is attributable to the smaller distance between the driver and the sight obstruction (i.e., the guardrail), with the result that the same sight line is obtained for both cases (i.e., flat-grade and crest).

By analysing the $A S D$ values for the two different vertical profiles, it can be observed that the presence of vertical curves impacts the sight distance: $A S D$ increases in presence of sag curves (from $A S D(\mathrm{~N} 2)=90 \mathrm{~m}$ and $A S D(\mathrm{H} 2)=75 \mathrm{~m}$ for "flat" profile to $A S D(\mathrm{~N} 2)=110 \mathrm{~m}$ and $A S D(\mathrm{H} 2)=85 \mathrm{~m}$ for "sag" profile, for $R=85 \mathrm{~m}$, left-hand curve; from $A S D(\mathrm{~N} 2)=110 \mathrm{~m}$ and $A S D(\mathrm{H} 2)=90 \mathrm{~m}$ for "flat" profile to $A S D(\mathrm{~N} 2)=135 \mathrm{~m}$ and $A S D(\mathrm{H} 2)=105 \mathrm{~m}$ for "sag" profile, for $R=130 \mathrm{~m}$, left-hand-curve). Although safety conditions are usually met in the left-hand curves, it is clear that crest vertical curves decrease the $A S D$ values (from $A S D(\mathrm{~N} 2)=210 \mathrm{~m}$ and $A S D(\mathrm{H} 2)=170 \mathrm{~m}$ for "flat" profile to $A S D(\mathrm{~N} 2)=180 \mathrm{~m}$ and $A S D(\mathrm{H} 2)=155 \mathrm{~m}$ for "crest" profile, for $R=450 \mathrm{~m}$, left-hand curve).

The results documented in this manuscript are consistent with those obtained by Sarhan and Hassan (2012), where they found that crests provide reduced ASD values, while sags increase the ASD in comparison to the flat-grade terrain case in the presence of concrete barriers. In particular, as the absolute value of $K_{v}$ decreases, $A S D$ increases on sag curves and decreases on crests. Reduced lateral offsets were also found to affect negatively sight distance conditions. In this sense, the research results are also in line with preliminary results of the authors on existing highways in the presence of concrete barriers (De Santos-Berbel et al. 2018). 


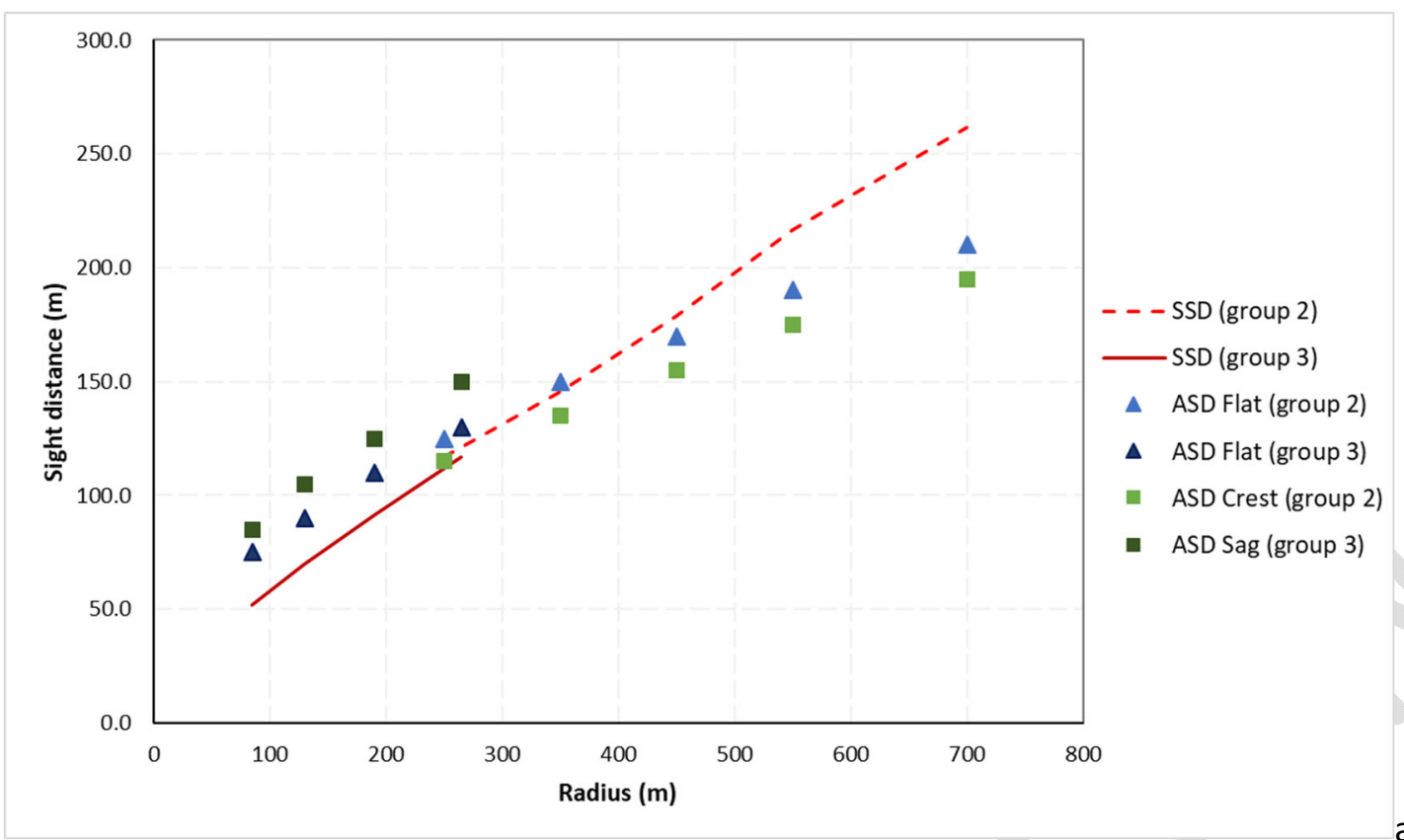

a)

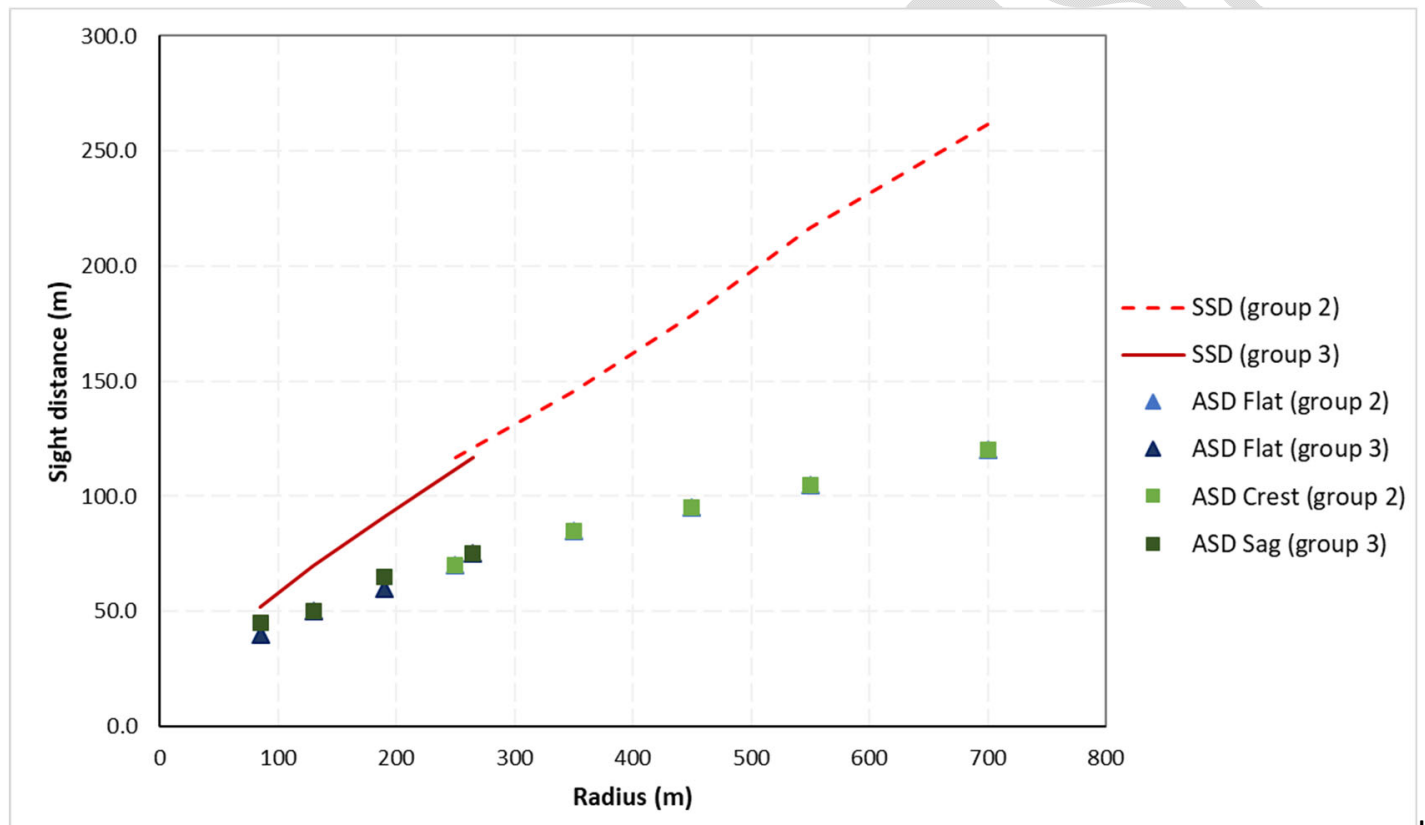

b)

412

413

Figure 9. Sight distance analysis as a function of the horizontal radius on curves overlapped with $\mathrm{H} 2$ barrier: a) left-hand curves, b) right-hand curves.

\section{Conclusions}

\section{Research contribution}

Previous studies demonstrated that GIS is a useful tool to carry out sight distance analyses on 3D models developed on existing road segments as well as on road projects. At present, no other modelling technique can provide reliable and fast results on road design scenarios. This study intended 
421

to assess the variations of $A S D$ due to different safety barrier types (i.e., their height) which can result from a difference in the design decision or cross-country difference in road standards. To this aim, the Shape Bender extension in the SketchUp Pro 2019 environment was used to adapt barriers to terrain models depicting different combinations of horizontal and vertical alignment. This tool greatly facilitates the 3D design, and it is particularly useful for roads and infrastructures.

GIS tools are useful to understand the effects of two different guardrail models on the ASD in curves. The use of multipatch features allows considering in the analysis sight obstruction previously modelled through 3D drawing software. As in this case, a faithful 3D reproduction of the guardrails allows to obtain reliable results, with a minimum of error, compared to other methods that may be more lacking.

\section{Implications}

Road designers should be aware of the impact of safety barriers on the ASD when considering the installation of barriers. The presence of taller barriers, even though they can provide greater containment levels, offer a reduced ASD value: in particular, worse visibility conditions detect in the presence of the 3-waves barrier ( $\mathrm{H} 2$ guardrail) compared to the N2 type. Given that the N2 barrier has a lower height, it enabled greater ASD.

As the radius of the horizontal curve increases, it becomes more difficult to ensure $A S D$ values that allow safe braking manoeuvres. It is demonstrated in group 2 curves (those with larger radii of curvature): as the radius increases, the difference between SSD and ASD increases too. This result is consistent with expectations because of the link between curve radii and design speed values (the higher the radius, the higher the design speed).

The worst sight conditions are certainly detected on right-hand curves. Comparing the curves, the $A S D$ values are greater in the left-hand bends than in the right-hand ones. Again, this is consistent with expectations because of the dependence of ASD from the distance of the observer from the sight obstruction (the smaller the distance, the smaller the ASD). 
From different comparisons involving the vertical profile and the dimensions of the curves, it is possible to see how the vertical profile affects the sight distance. Sag vertical curves increase ASD values, while the presence of horizontal curves overlapped with crest vertical curves worsens the sight conditions compared to a flat-grade terrain, especially in left-hand curves.

451

\section{Limitations and future research needs}

453

This work is limited to the specific road type and the two guardrails considered. Other analysis should be carried out with the aim of extend the results to different road and barrier typologies. Furthermore, the position for the barrier in the roadside (or in the median) is another factor that affects the ASD and that deserve specific analysis. The comparison between rigid and guardrails with different heights and shapes will provide other insight on the effects of these road furniture on the ASD.

As future lines of research, the authors are working on a driving simulator study to check whether the driver perceives and adapt their behavior to the different sight distance condition along curves treated with the two different barriers.

\section{Data Availability Statement}

Some or all data, models, or code that support the findings of this study are available from the corresponding author upon reasonable request.

\section{Acknowledgments}

The Spanish Ministerio de Economía y Competitividad and the European Regional Development Fund (FEDER) for research project TRA2015-63579-R (MINECO/FEDER), and the European Union Erasmus+ Programme funded this project. This Manuscript reflects the views only of the authors, and the Commission cannot be held responsible for any use which may be made of the information contained therein. 
472

473

474

475

476

\section{References}

Alcón Gil, P., De Santos-Berbel, C., and Castro, M. (2021). "Driver glare exposure with different vehicle frontlighting systems." Journal of Safety Research, National Safety Council and Elsevier Ltd, 76, 228-237. https://doi.org/10.1016/j.jsr.2020.12.018

American Association of State Highway and Transportation Officials (AASHTO). (2011). Roadside Design Guide. Washington, D.C.

American Association of State Highway and Transportation Officials (AASHTO). (2018). A policy on geometric design of highways and streets. AASHTO, Washington, D.C.

Bassani, M., Grasso, N., and Piras, M. (2015). "3D GIS based evaluation of the available sight distance to assess safety of urban roads." International Archives of the Photogrammetry, Remote Sensing and Spatial Information Sciences - ISPRS Archives, 40, 137-143. https://doi.org/10.5194/isprsarchives-XL-3-W3-137-2015

Bassani, M., Grasso, N., Piras, M., and Catani, L. (2016). “Estimating the available sight distance on urban roads by integrating 3D maps and low-cost mobile mapping systems into a GIS numerical computing environment." Transportation Research Board 95th Annual Meeting, Washington D.C.

Bassani, M., Grasso, N., Piras, M., and Catani, L. (2019). “Estimating the available sight distance in the urban environment by GIS and numerical computing codes." ISPRS International Journal of GeoInformation, 8(2), 69. https://doi.org/10.3390/ijgi8020069

Campoy Ungria, J. M. (2015). “Nueva Metodología Para La Obtención De Distancias De Visibilidad Disponibles En Carreteras Existentes Basada En Datos Lidar Terrestre." Universidad Politécnica de Valencia, Valencia, Spain.

Castro, M., Anta, J. A., Iglesias, L., and Sánchez, J. A. (2014). “GIS-Based System for Sight Distance Analysis of Highways." ASCE Journal of Computing in Civil Engineering, 28(3): 04014005. https://doi.org/10.1061/(ASCE)CP.1943-5487.0000317

Castro, M., and De Santos-Berbel, C. (2015). "Spatial analysis of geometric design consistency and road 
sight distance." International Journal of Geographical Information Science, 29(12), 2061-2074. https://doi.org/10.1080/13658816.2015.1037304

Castro, M., De Santos-Berbel, C., and Iglesias, L. (2017). "A comprehensive methodology for the analysis of highway sight distance." Transport Infrastructure and Systems: Proceedings of the AllT, 193-200, Rome, Italy: Associazione Italiana per l'Ingegneria del Traffico e dei Transporti.

Castro, M., Iglesias, L., Sánchez, J. Á., and Ambrosio, L. (2011). "Sight distance analysis of highways using GIS tools." Transportation Research Part C: Emerging Technologies, 19(6), 997-1005. https://doi.org/10.1016/j.trc.2011.05.012

Castro, M., López-Cuervo, S., Paréns-González, M., and de Santos-Berbel, C. (2016). “LIDAR-based roadway and roadside modelling for sight distance studies." Survey Review, 48(350), 309-315. https://doi.org/10.1179/1752270615Y.0000000037

De Santos-Berbel, C., Anta, J. A., Castro, M., and Iglesias, L. (2013). "Sight distance for road safety analysis using GIS." Esri Middle East Africa User Conference (EMEAUC), 1-9. Munich, Germany: Esri Deutschland GmbH.

De Santos-Berbel, C., and Castro, M. (2018). "Three-dimensional virtual highway model for sightdistance evaluation of highway underpasses." Journal of Surveying Engineering, 144(4), 05018003. https://doi.org/10.1061/(ASCE)SU.1943-5428.0000258

De Santos-Berbel, C., González-Gómez, K., Castro, M., and Anta, J. A. (2018). “Addressing sightdistance-related safety effects of installing median barriers at horizontal curves of undivided highways under a 3D approach." 5th International Conference on Road and Rail Infrastructure (CETRA), 1067-1073. Zadar, Croatia: University of Zagreb.

Environmental Science Research Insitute (ESRI). (2008). The multipatch geometry type. Redlands, California.

Environmental Science Research Institute (ESRI). (2021a). "Line of sight." Accessed May 28, 2021. https://desktop.arcgis.com/en/arcmap/latest/tools/3d-analyst-toolbox/line-of-sight.htm

Environmental Science Research Institute (ESRI). (2021b). "Construct sight lines." Accessed May 28, 
2021. https://desktop.arcgis.com/en/arcmap/latest/tools/3d-analyst-toolbox/construct-sight$\underline{\text { lines.htm }}$

European Committee for Standardization (CEN). (2002). “ENV 1317-4. Road restraint systems. Part 4. Performance classes, impact test acceptance criteria and test methods for terminals and transitions of safety barriers."

European Committee for Standardization (CEN). (2011a). “EN 1317-1. Road restraint systems. Part 1: Terminology and general criteria for test methods." Brussels, Belgium.

European Committee for Standardization (CEN). (2011b). “EN 1317-2. Road restraint systems. Part 2: Performance classes, impact test acceptance criteria and test methods for safety barriers including vehicle parapets."

European Committee for Standardization (CEN). (2012). "EN 1317-5. Road restraint systems. Part 5: Product requirements and evaluation of conformity for vehicle restraint systems."

Gargoum, S. A., and El-Basyouny, K. (2020). "Analyzing the ability of crash-prone highways to handle stochastically modelled driver demand for stopping sight distance." Accident Analysis and Prevention, Elsevier, 136. https://doi.org/10.1016/j.aap.2019.105395

Gargoum, S. A., El-Basyouny, K., and Sabbagh, J. (2018). “Assessing Stopping and Passing Sight Distance on Highways Using Mobile LiDAR Data." Journal of Computing in Civil Engineering, 32(4), 1-13.

\section{https://doi.org/10.1061/(ASCE)CP.1943-5487.0000753}

Ibrahim, S. E. B., and Sayed, T. (2011). "Developing safety performance functions incorporating reliability-based risk measures." Accident Analysis \& Prevention, Elsevier Ltd, 43(6), 2153-2159. https://doi.org/10.1016/j.aap.2011.06.006

Iglesias, L., Castro, M., Pascual Gallego, V., and De Santos-Berbel, C. (2016). "Estimation of sight distance on highways with overhanging elements." 3rd International Conference on Traffic and Transport Engineering (ICTTE), 75-82. Belgrade, Serbia: City Net Scientific Research Center Ltd.

Iglesias, L., De Santos-Berbel, C., Pascual, V., and Castro, M. (2019). “Using small unmanned aerial vehicle in 3D modeling of highways with tree-covered roadsides to estimate sight distance." 


\section{Remote Sensing, 11(2625), 1-13. https://doi.org/10.3390/rs11222625}

Ismail, K. A., and Sayed, T. (2007). "New algorithm for calculating 3D available sight distance." Journal of Transportation Engineering, 133(10), 572-581. https://doi.org/10.1061/(ASCE)0733-

\section{$\underline{947 \times(2007) 133: 10(572)}$}

Jung, J., Olsen, M. J., Hurwitz, D. S., Kashani, A. G., and Buker, K. (2018). “3D virtual intersection sight distance analysis using lidar data." Transportation Research Part C: Emerging Technologies, Elsevier, 86(August 2017), 563-579. https://doi.org/10.1016/j.trc.2017.12.004

Khattak, A. J., and Shamayleh, H. (2005). "Highway safety assessment through geographic information system-based data visualization." Journal of Computing in Civil Engineering, 19(4), 407-411. https://doi.org/10.1061/(ASCE)0887-3801(2005)19:4(407)

Liu, C. (2013). "Exact sight distance determination on compound vertical and horizontal curves in the presence of road barriers." International Journal of Transportation Science and Technology, 2(2), 159-166. https://doi.org/10.1260/2046-0430.2.2.159

Ma, Y., Zheng, Y., Cheng, J., and Easa, S. M. (2019). "Real-time visualization method for estimating 3D highway sight distance using LiDAR data." Journal of Transportation Engineering Part A: Systems, 145(4): 04019006. https://doi.org/10.1061/JTEPBS.0000228

Ma, Y., Zheng, Y., Cheng, J., Guo, L., and Zhang, Y. (2018). “A novel real-time visualization algorithm for computing three- dimensional sight distance." Transportation Research Board Annual Meeting, (979).

Ministerio de Fomento. (2009). Orden circular 28/2009 sobre criterios de aplicación de barreras de seguridad metálicas. España.

Ministerio de Fomento. (2014). Orden Circular 35/2014 sobre criterios de aplicación de sistemas de contención de vehículos. España.

Ministerio de Fomento. (2016). Instrucción de carreteras. Norma 3.1-IC. España.

Ministero delle Infrastrutture e dei Trasporti. (2001). Norme funzionali e geometriche per la costruzione delle strade. Rome, Italy. 
Ministero delle Infrastrutture e dei Trasporti. (2004). Istruzioni tecniche per la progettazione, l'omologazione e l'impiego dei dispositivi di ritenuta nelle costruzioni stradali. Rome, Italy.

Montella, A. (2001). "Selection of roadside safety barrier containment level according to European Union Standards." Transportation Research Record, (1743), 104-110.

\section{https://doi.org/10.3141/1743-14}

Papadimitriou, E., Mavromatis, S., and Psarianos, B. (2018). "Stopping sight distance adequacy assessment on freeways: the case of left horizontal curves over crest vertical curves." Transportation Letters, 10(5), 269-279. https://doi.org/10.1080/19427867.2016.1259759

Sarhan, M., and Hassan, Y. (2012). "Consideration of sight distance in placement of concrete barriers on horizontal curves of roads." Transportation Research Record, (2301), 9-16.

\section{https://doi.org/10.3141/2301-02}

Shalkamy, A., El-Basyouny, K., and Xu, H. Y. (2020). “Voxel-based methodology for automated 3d sight distance assessment on highways using mobile light detection and ranging data." Transportation Research Record, 2674(5), 587-599. https://doi.org/10.1177/0361198120917376

Steinauer, B., and Mayer, G. (1999). "Sicherheitsdefizite in der Straßenplanung." Straße und Autobahn, 12(99), 655-662.

TOOL S.A. (2013). Manual de instrucciones del programa CLIP sobre windows. Madrid, Spain. TOOL, S.A.

Trimble. (2013). “Extension Warehouse: CLF Shape Bender tool.” Accessed December 6, 2020. https://extensions.sketchup.com/extension/8a4d10ff-40f3-4885-b8ba-1dac2b941885/clfshape-bender

Wang, J., Lawson, G., and Shen, Y. (2014). “Advances in Engineering Software Automatic high-fidelity 3D road network modeling based on 2D GIS data." Advances in Engineering Software, Elsevier Ltd, 76, 86-98. https://doi.org/10.1016 716/j.advengsoft.2014.06.005

Wang, J., Zhou, H., and Zhang, Y. (2017). "Improve sight distance at signalized ramp terminals of partial-cloverleaf interchanges to deter wrong-way entries." Journal of Transportation 
